Diabetologia 8, 215-220 (1972)

(c) by Springer-Verlag 1972

\title{
The Role of Endogenous Insulin in Different Hyperlipidemic States
}

\author{
M. Tzagodrnis, R. Chiles, J. Herrold, and T. Skmuman \\ Department of Medicine, Division of Endocrinology \& Metabolism, The Ohio State University Hospitals, Columbus, \\ Ohio U.S.A. \\ Received, January 31, 1972, accepted: February 22, 1972
}

Summary. The relationship of insulin secretion to different types of lipid disorders was studied in 54 nonobese coronary patients with hyperlipidemia. Nineteen patients had hypercholesterolemia and normal triglycerides (type II), and 35 had endogenous hypertriglyceridemia with or without elevated cholesterol levels. Carbohydrate abnormalities and increased insulin concentrations were much more frequent in the hypertriglyceridemic group than in the type II group. Treatment designed to lower insulin levels resulted in no significant serum lipid changes in the type II subjects. In those with hypertriglyceridemia, a decrease in insulin accompanied appreciable falls in triglyceride and cholesterol levels. Mild carbohydrate abnormalities with insulin hypersecretion were closely associated with endogenous hypertriglyceridemia, but appeared to play no major role in type II hyperlipidemia.

Le rôle de l'insuline endogène dans différents états d'hyperlipidémie

Résumé. La relation entre la sécrétion d'insuline et différents types de perturbations lipidiques a été étudiée chez 54 patients coronariens non-obèses, présentant une hyperlipidémie. Dix-neuf patients avaient de l'hypercholestérolémie et des taux de triglycérides normaux (type II), et 35 avaient de l'hypertriglycéridémie endogène avec ou sans élévation des taux de cholestérol. Les anomalies des hydrates de carbone et les concentrations élevées d'insuline étaient bien plus fréquentes dans le groupe hypertriglycéridémique que dans le groupe du type II. Un traitement destiné à abaisser les taux d'insuline n'a pas provoqué de modifications significatives des lipides sériques chez les sujets du type II. Chez les sujets ayant une hypertriglycéridémie, une diminution du taux d'insuline accompagnait des diminutions appréciables des taux de triglycérides et de cholestérol. De légères anomalies des hydrates de carbone ainsi qu'une hypersécrétion d'insuline étaient étroitement liées à l'hypertriglycéridémie endogène, mais ne semblaient pas jouer un rôle majeur dans l'hyperlipidémie du type II.

Die Rolle des endogenen Insulins bei verschiedenen hyperlipidämischen Zuständen

Zusammenfassung. Bei 54 nicht übergewichtigen Koronarpatienten mit Hyperlipidämie wurde die Beziehung der Insulinsekretion zu verschiedenen Arten von Lipidstörungen untersucht. 19 Patienten hatten eine Hypercholesterinämie und normale Triglyceridspiegel (Typ II ), 35 hatten eine endogene Hypertriglycerinämie mit oder ohne erhöhten Cholesterinspiegel. Anomalien des Kohlenhydratstoffwechsels und erhöhte Insulinkonzentrationen wurden viel häufiger in der Gruppe der Hypertriglycerinämien als in der Gruppe des Typ II angetroffen. Eine den Insulinspiegel senkende Behandlung führte nicht zu signifikanten Änderungen der Serumlipide bei den Fällen des Typ II. Bei den Hypertriglycerinämien wurde die Insulinverminderung von einem beträchtlichen Abfall der Triglycerid- und Cholesterinspiegel begleitet. Geringe Anomalien des Kohlenhydrat. stoffwechsels mit Insulinhypersekretion waren eng mit einer endogenen Hypertriglycerinämie verknüpft, schienen aber keine größere Rolle bei den Hyperlipidämien des Typ II zu spielen.

Key words: Insulin secretion, Hyperlipidemia, Hyper cholesterolemia, Hypertriglyceridemia.
Disorders in lipid and carbohydrate metabolism are common in patients with coronary heart disease $[1,2,3]$. The lipid patterns of coronary patients may be characterized as either isolated hypercholesterolemia, or hypertriglyceridemia with or without elevated cholesterol levels $[4,5,6]$. Abnormalities in glucose tolerance, even though minor, appear to increase the risk of developing clinical manifestations of atherosclerosis [7].

We have recently reported that a high frequency of abnormalities in serum lipid levels, glucose tolerance, and insulin responses was found in young patients with coronary disease [8]. A positive correlation was noted between fasting triglycerides and the magnitude of glucose-induced insulin secretion. Since hyperlipidemia and hyperglycemia can be influenced by changes in insulin secretion, body weight, or dietary intake [9], this study evaluates the initial relationships between the types of lipid abnormalities and glucose-induced insulin secretion in coronary patients. We also observed what effect lowering insulin levels had on serum lipids. The results confirm previous evidence that insulin hypersecretion is closely associated with and possibly causally related to endogenous hypertriglyceridemia. They further suggest that insulin secretion is not a controlling factor in regulation of cholesterol levels in patients with hypercholesterolemia without hypertriglyceridemia.

\section{Methods}

\section{Patient Selection}

The patients were selected from a group of 100 young (age 24 to 49 ), non-obese (less than $115 \%$ ideal body weight according to Metropolitan Life Insurance Company tables) subjects who were hospitalized for coronary disease. Those with known diabetes were excluded. The diagnosis of coronary heart disease was established by: 1. a definite myocardial infarction (electrocardiographic 
and/or serum enzyme changes; 2 . presence of angina pectoris associated with angiographic evidence of coronary atherosclerosis; or 3. angina pectoris associated with electrocardiographic evidence of coronary insufficiency. A control group of $\mathbf{3 7}$ subjects without known coronary disease aged 26 to 50 years, and weighing less than $115 \%$ ideal body weight had fasting lipid determinations and a glucose tolerance test with insulin measurements for purposes of comparison. No repeat testing was performed on the controls. Four of these subjects had elevated cholesterol and/or triglyceride levels. Their mean cholesterol value was $220 \mathrm{mg}$ per $100 \mathrm{ml}$ (range 131-321) and the mean triglycerides $80 \mathrm{mg}$ per $100 \mathrm{ml}$ (range $10-258$ ).

\section{Classification of Hyperlipidemia}

Fifty-four of the 100 patients were arbitrarily designated as having hyperlipidemia. The method of making this selection consisted of establishing that the fasting serum cholesterol exceeded $290 \mathrm{mg} \%$ or the fasting serum triglycerides exceeded $180 \mathrm{mg} \%$, or both. Cholesterol was measured according to the method of Abell et al. [10] and triglycerides by the methods of Stern and Shapiro [11] and Laurell [12]. All lipid studies were made a month or longer after myocardial infarction. Lipoprotein electrophoresis was done in all patients except a few of those with hypercholesterolemia and normal triglycerides. Familial hyperlipidemia can be divided into five different types based upon concentrations of different plasma lipoproteins $[13,14]$. Secondary hyperlipidemias such as those due to thyroid disorders or liver disease were excluded by clinical examination and appropriate screening laboratory tests. Two groups of patients were classified as hyperlipidemias based on 1. an elevated cholesterol level without hypertriglyceridemia, and 2. elevated endogenous triglycerides with or without hypercholesterolemia.

The Type II hyperlipidemic group consisted of 19 patients who had hypercholesterolemia and normal triglycerides. Familial Type II is hyperbeta-lipoproteinemia with or without increased pre-beta lipoproteins, a definition based on study of many kindreds [14]. One must determine directly or indirectly whether beta lipoproteins are increased to diagnose familial Type II hyperlipidemia. This was not done on all patients in this group.

The other group consisted of 35 subjects with elevated endogenous triglyceride levels, with or without cholesterol elevation (mixed group). The electrophoretic patterns of the mixed group consisted of Type III, Type IV, and a third pattern in which both the beta and pre-beta bands were distinctly separated and densely stained. Type III is defined by the presence of abnormal lipoproteins [15]. Special techniques such as ultracentrifugation or electrophoresis on both poly. acrylamide gel and paper were not carried out to clearly differentiate this type from others. Those subjects with patterns in which both the beta and prebeta bands were densely stained may represent the variant of familial Type II in which pre-beta lipoproteins are elevated in addition to beta lipoproteins. It may also be the "mixed type" of acquired hyperlipoproteinemia that some believe is different from Type II [16]. Two Type $V$ subjects who had significant staining at the origin (chylomicrons) were excluded.

\section{Evaluation of Insulin Secretion}

A 3-h oral glucose tolerance test using $240 \mathrm{ml}$ of Glucola ${ }^{\circledR}$ (75 grams) was done at the time of lipid measurements. Serum glucose was estimated by the autoanalyzer, and serum immunoreactive insulin by the method of Grodsky and Forsham [17]. Insulin values from specimens obtained at $0,1 / 2,1,2$, and $3 \mathrm{~h}$ were used to calculate the area under the 3 -h curve in $\mathrm{mU}$-min (milliunit minutes). The formula used for the calculation was: Area $=[(1 / 2$ (fasting level) $+(1 / 2 h$ level $)+1 \frac{1}{2}(1 \mathrm{~h}$ level $)+2(2 \mathrm{~h}$ level $)+(3 \mathrm{~h}$ level $\left.)\right]$ $\times 30$. All subjects were told to eat a regular diet for two days before the tests.

\section{Assessment of the effects of diet and phenformin on insulin and lipid levels}

After the initial study, therapy was begun to try to reduce insulin secretion by administering phenformin, a drug known to decrease insulin responsiveness to glucose leading, and by employing a diet low in simple sugars. The daily dose of phenformin was 50 to $150 \mathrm{mg}$. The smaller dose was begun initially, then an increase to 100 or $150 \mathrm{mg}$ daily was made about 2 months later. If the patients noticed gastrointestinal symptoms or a metallic taste, the dose was decreased to $50 \mathrm{mg}$ per day and maintained at that level. In practice, the diet eliminated free sugar, desserts, soft drinks and jellies, but not fruit. In patients with elevated cholesterol levels, a low cholesterol-proportioned fat diet similar to that used by the Anti-Coronary Club was also prescribed [18]. No mention of exact calories was made to the patients. As more patients entered the study, a group on diet alone was also established. Thus, when a subject agreed to participate, treatment with phenformin plus diet, or diet alone, was prescribed randomly. Two months after treatment and then again at regular intervals, an oral glucose tolerance test was repeated and serum lipids were remeasured. Statistical analysis by "students" t" test was done to determine significant differences between means of paired data by comparing the initial values with those obtained after treatment.

\section{Results}

The Type II hyperlipidemic group had a mean serum cholesterol level of 357 and triglycerides of $81 \mathrm{mg}$ per $100 \mathrm{ml}$. The patients with endogenous hypertriglyceridemia had mean concentrations of $317 \mathrm{mg}$ per $100 \mathrm{ml}$ cholesterol and $376 \mathrm{mg}$ per $100 \mathrm{ml}$ tri- 
glycerides. Thirteen $(37 \%)$ of the 35 patients in the latter group had cholesterol levels less than $290 \mathrm{mg}$ per $100 \mathrm{ml}$.

\section{Glucose tolerance tests and insulin response}

Since known diabetics were excluded, the actual frequency of glucose intolerance in unselected hyperlipidemic subjects is not represented by this study.
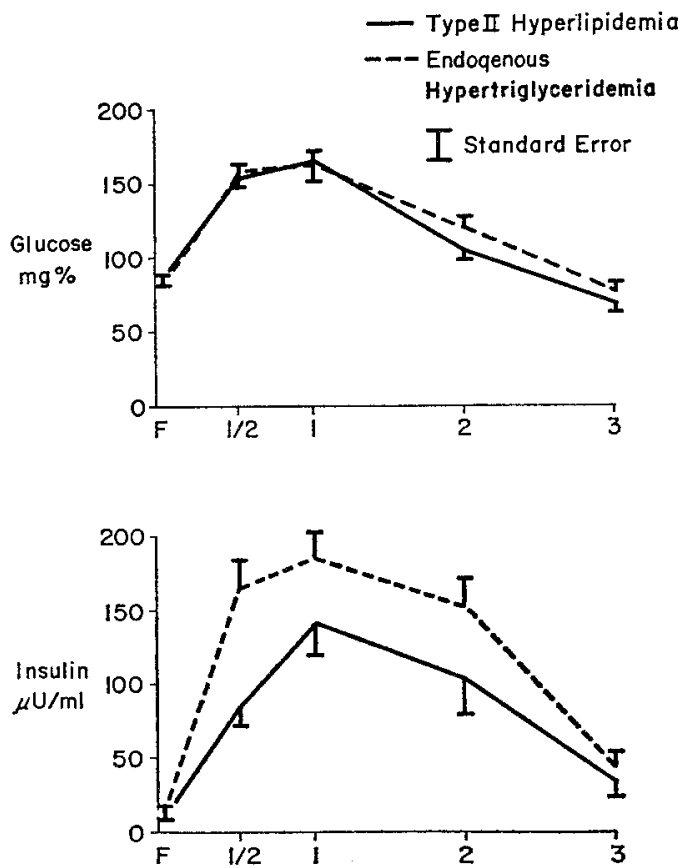

Fig. 1. Comparison of mean and one standard error of glucose (above) and insulin (below) values during a glucose tolerance test in 19 patients with Type II hyperlipidemia and 35 patients with endogenous hypertriglyceridemia with or without hypercholesterolemia
An abnormal serum insulin response, manifested by one or more elevated levels, or delayed peak levels occurring after the 1-h interval, was found in six of the Type II group and 22 of the mixed group (Table 1). The insulin response was considered elevated if it exceeded the mean plus two standard deviations of control subjects). The mean insulin response of the mixed group was higher at each interval after glucose than that observed in the Type II group (Fig. 1).

An estimation of the total insulin concentration was made by calculating the area under the $3-\mathrm{h}$ insulin curve. The mean insulin area of the group with endogenous hypertriglyceridemia was $24 \pm 2 \mathrm{mU}$-min. This was significantly higher $(p<0.05)$ than the $16 \pm 3$ mU-min found in the 19 Type II patients.

\section{The effects of phenformin and diet in the mixed hyper- lipidemic group}

Twenty-seven of the patients with endogenous hypertriglyceridemia were treated with phenformin and diet while the other eight were treated a low simple sugar diet. After two months of therapy, the mean area under the 3 -h insulin curve for the total group decreased from 24 to $17 \mathrm{mU}-\min (p<0.05)$. The decrease in insulin secretion was accompanied by impressive falls in the levels of cholesterol and triglyceride (Fig. 2). The mean serum triglyceride concentration of 376 decreased to $196 \mathrm{mg}$ per $100 \mathrm{ml}$ after two months of treatment $(p<0.01)$. The serum cholesterol level of 317 concommitantly fell to $276 \mathrm{mg}$ per $100 \mathrm{ml}(p<0.02)$. After continued treatment for an average of 17 months, the triglyceride level was 195 and the cholesterol was $266 \mathrm{mg}$ per $100 \mathrm{ml}$, both significantly different from initial values $(p<0.01)$.

The mean weight of the group decreased from 170 to 164 after two months and finally at 157 pounds.

Table 1. Carbohydrate and Insulin Abnormalities Found in the Tested Subjects

\begin{tabular}{|c|c|c|c|}
\hline Abnormalities ${ }^{a}$ & 37 Control Subjects & $\begin{array}{l}19 \text { Patients With } \\
\text { Type II Hyper- } \\
\text { lipidemia }\end{array}$ & $\begin{array}{l}35 \text { Patients With } \\
\text { Endogenous Hyper- } \\
\text { triglyceridemia }\end{array}$ \\
\hline Insulin Only & 5 & 4 & 16 \\
\hline Carbohydrate Only & 0 & 0 & 2 \\
\hline Insulin and carbohydrate & 1 & 2 & 6 \\
\hline Total Patients with abnormality & $6(16 \%)$ & $6(31 \%)$ & $24(68 \%)$ \\
\hline
\end{tabular}

a Abnormalities: Insulin-response manifested by elevated level or by delayed secretion; carbohydrate-abnormal glucose tolerance test (Probable or definite diabetes)

However, only two of the 19 patients with Type II hyperlipidemia compared to seven of the 35 patients with endogenous hypertriglyceridemia had possible or definite diabetes according to the criteria of Wilkerson [19]. No subjects had a fasting serum glucose level above $115 \mathrm{mg}$ per $100 \mathrm{ml}$. Fig. 1 compares the mean glucose values of the two hyperlipidemic groups.
Weight loss certainly played some role in the metabolic measurements noted since insulin and lipid concentrations are both influenced by body weight. However, 12 of the 35 patients gained slightly after treatment for two months. Of these, eight showed decreased insulin levels associated with lower triglycerides in spite of the weight gain. 


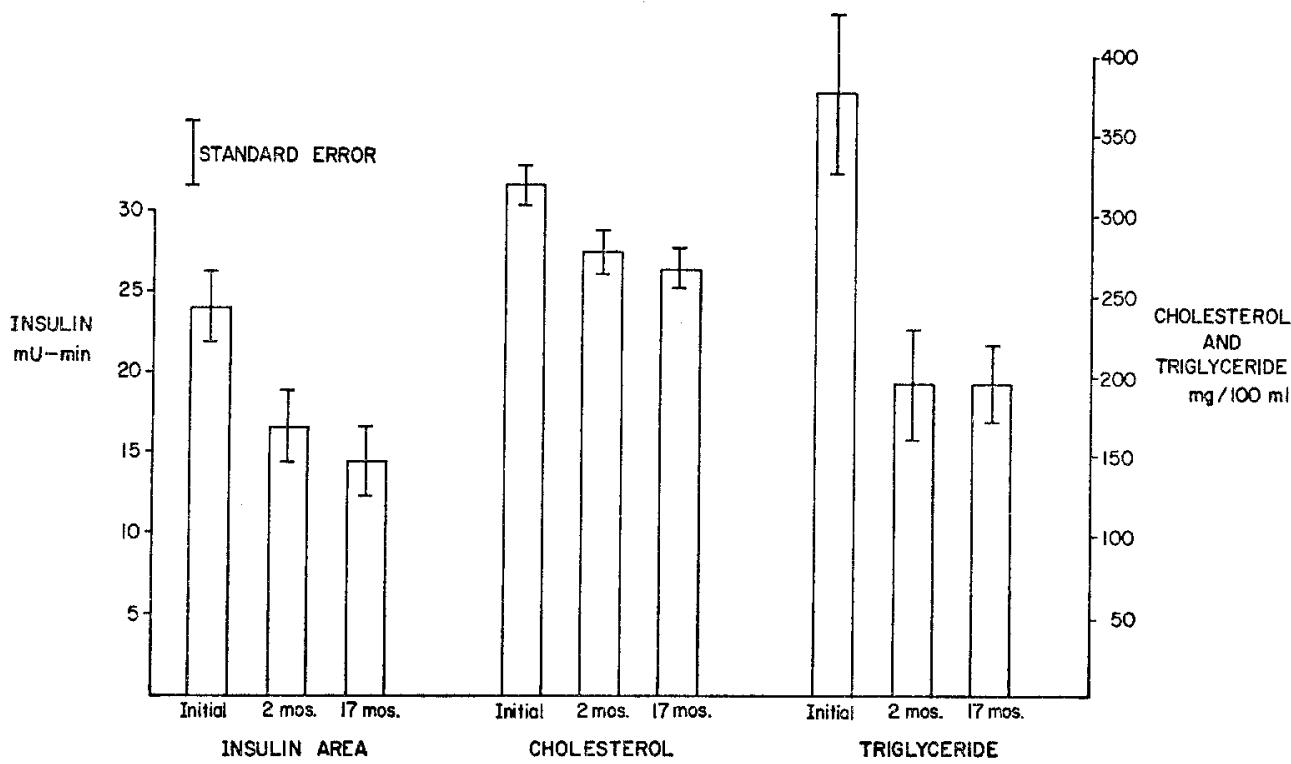

Fig. 2. Responses of insulin concentration (reflected by the area under the 3 -h curve) and serum cholesterol and triglyceride levels to treatment with phenformin plus diet or diet alone in $\mathbf{3 5}$ patients with endogenous hypertriglyceridemia

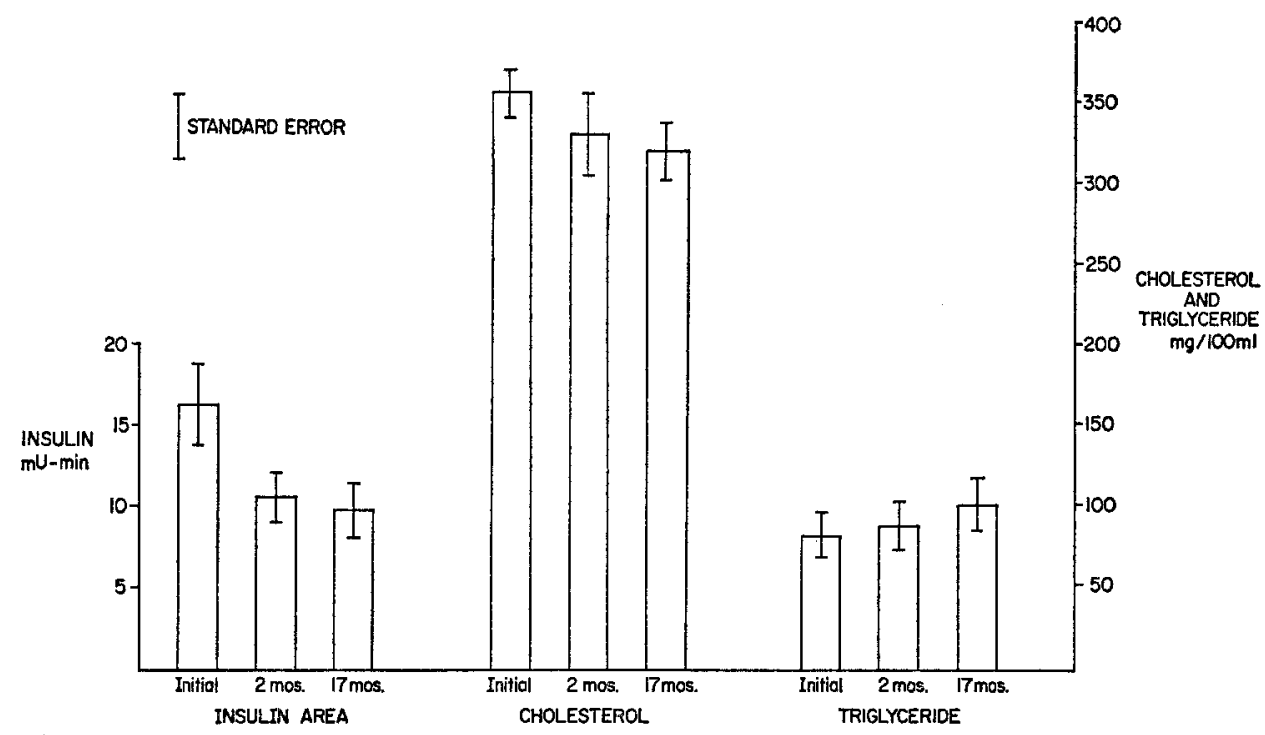

Fig. 3. Responses of insulin concentration and serum cholesterol and triglyceride levels to treatment with phenformin plus diet or diet alone in 19 patients with Type II hyperlipidemia

The effects of phenformin and diet in the type II hyperlipidemic group

Treatment resulted in a decrease of the mean insulin area from 16.3 to 10.5 after two months and to 9.7 mU-min $(p<0.10)$ after a mean of 17 months (Fig. 3). The small decrease in insulin concentration was associated with an insignificant rise in serum triglycerides from a mean level of 81 to 87 after two months and to $100 \mathrm{mg}$ per $100 \mathrm{ml}$ after 17 months treatment. Serum cholesterol levels decreased from 357 to 333 after two months and to $321 \mathrm{mg}$ per $100 \mathrm{ml}$ (not significant) after a mean follow-up of 17 months. As a group, these subjects reduced from 158 to 152 pounds.

Thirteen of the Type II patients were treated with phenformin and low-cholesterol-proportioned fat, low simple sugar diet, while the other six were treated by diet alone. Although there was a tendency toward lower insulin concentrations, decreased serum cholesterol levels, and increased triglycerides, only the final set of insulin concentrations in the phenformin treated. patients approached statistically significant values (Table 2). 


\section{Comparison of hypercholesterolemic subjects in both groups}

Twenty two patients in the mixed group had elevated cholesterol levels (exceeding $290 \mathrm{mg}$ per $\mathrm{ml}$ ). A comparison of the mean cholesterol changes were made between these patients versus the Type II group. The initial mean cholesterol value for the 22 patients with both triglyceride and cholesterol elevations was $352 \pm 13$ (1 SEM) mg per $100 \mathrm{ml}$, quite similar to the mean level of $357 \mathrm{mg}$ per $100 \mathrm{ml}$ found in the total Type II group. Treatment resulted in a decrease of the cholesterol to $297(p<0.05)$ after two months and later to $278 \mathrm{mg}$ per $100 \mathrm{ml}(p<0.01)$, quite different from the minimal changes noted in the Type II group. suggest that increased endogenous insulin secretion plays a major role in the hyperlipidemia of the mixed group. Insulin hypersecretion does not seem to be of importance in Type II hyperlipidemia. This thesis is consistent with the physiologic role of insulin. Besides its well known action to increase glucose uptake by cells, insulin facilitates lipid storage both by enhancing fatty acid synthesis and inhibiting lipolysis. Triglycerides synthesized in the liver are transported in the blood stream to a large extent in the form of pre-beta lipoproteins.

The concept that endogenous hypertriglyceridemia might have been induced by an exaggerated secretion of insulin is in accord with previously reported studies by Farquhar et al. [20] and Reaven et al. [21]. Several

Table 2. Effect of Diet and Phenformin Plus Diet on Mean \pm 1 SEM. Insulin (mU-min) and Lipid (mg per 100 ml)

Responses

\begin{tabular}{|c|c|c|c|c|c|c|c|c|c|c|}
\hline \multirow{2}{*}{$\begin{array}{l}\text { Endogenous } \\
\text { Hypertriglyceridemia }\end{array}$} & \multicolumn{4}{|c|}{ Insulin Area } & \multicolumn{2}{|c|}{ Triglycerides } & \multirow[b]{2}{*}{ Final } & \multicolumn{2}{|c|}{ Cholesterol } & \multirow[b]{2}{*}{ Final } \\
\hline & rour & Initial & 2 Month & Final & Initial & 2 Month & & Initial & 2 Month & \\
\hline & & & & & & $1 \mathrm{~b}$ & & & & \\
\hline & & 2 & & & & 23 & & & & \\
\hline $\begin{array}{l}\text { Total Group Mean } \\
\text { Type II Hyperlipide }\end{array}$ & $(35)$ & $24 \pm$ & $17 \pm 2$ & 15 & 37 & 19 & 19 & 317 & $276 \pm 13^{\mathrm{a}}$ & $266 \pm 1$ \\
\hline Diet alone & $\begin{array}{l}\text { Grou } \\
(6)\end{array}$ & 11 & & & & & & & & \\
\hline & (13) & $19 \pm 3$ & $12 \pm$ & $9 \pm$ & & & & & & \\
\hline Total Group Meas & (19) & $16 \pm 3$ & $11 \pm 2$ & $10 \pm 2$ & & 87 & 100 & & & 321 \\
\hline
\end{tabular}

a $P<0.05$ Comparisons with initial values

b $P<0.01$

\section{Discussion}

The baseline findings in our coronary patients showed a high frequency of carbohydrate and insulin abnormalities in those with endogenous hypertriglyceridemia. Also, the mean insulin concentration during a 3-h glucose tolerance test was significantly greater in the mixed group as compared to the group with Type II hyperlipidemia. These initial studies suggested that possibly glucose and insulin abnormalities had a close relationship to the hypertriglyceridemia in at least some patients in the mixed group.

To further study this relationship, attempts were made to lower insulin levels to see what effect this had on serum lipids. This was accomplished alone or in combination, by phenformin, a simple sugar restricted diet, loss of weight, and possibly other factors. A reduction of insulin concentration in the endogenous hypertriglyceridemic group was associated with a decrease in cholesterol and triglyceride levels. In contrast, those individuals with Type II hyperlipidemia showed little or no response to therapeutic manipulation. Although a minor decrease in insulin concentration occurred in the Type III group, the cholesterol and triglyceride levels were basically unchanged.

Although associated metabolic abnormalities do not imply causal relationships between them, our data other investigators have emphasized the key role of insulin in hypertriglyceridemia under various situations in which insulin levels are increased such as obesity, mild diabetes, and the taking of oral contraceptives $[22,23,24,25]$. On the other hand, Glueck and co-workers [26] found no correlation between hypertriglyceridemia and insulin levels in familial Type IV hyperlipidemia. The reasons for these differences are not readily apparent. Insulin responses are quite variable among individuals and are influenced by body weight, the degree of glucose intolerance, diet, activity, and many other factors. Much of the experimental data dealing with insulin and triglyceride interrelationships have been recently reviewed by Nikkila [27].

It is likely that other mechanisms play important roles in endogenous hypertriglyceridemia. Hepatic conversion of free fatty acids (FFA) liberated from adipose tissue by a variety of stimuli [28] and transformation of exogenous triglyceride by the liver [29] are other sources of increased endogenous triglycerides. The severe insulin deficient diabetic, for example, may mobilize FFA in excess of the liver's capacity to oxidize them, and therefore, have endogenous hypertriglyceridemia. Since the subjects chosen for this study did not have exogenous hypertriglyceridemia, were not severely diabetic, and generally had a normal FFA response to a glucose load [30] these mechanisms of 
endogenous hypertriglyceridemia do not seem to be major ones. Our data suggest that high insulin levels play a major role in endogenous hypertriglyceridemia with or without hypercholesterolemia, but not in Type II hyperlipidemia.

Acknowledgements. This study was supported in part by the National Training Grant 2 TO 1 AMO 5118-13 and by a grant from the U.S. Pharmaceutical Corporation, New York, New York.

\section{References}

1. Falsetti, H.L., Schnatz, J.D., Greene, D. G., Bunnell, I.L.: Lipid and carbohydrate studies in coronary artery disease. Circulation 37, 184-191 (1968).

2. Tzagournis, M., Seidensticker, J.F., Hamwi, G.J.: Serum insulin, carbohydrate and lipid abnormalities in patients with premature coronary heart disease. Ann. intern. Med. 67, 42-47 (1967).

3. Blankenhorn, D.H., Chin, H.P., Law, F.R.K.: Ischemic heart disease in young adults: Metabolic and angiographic diagnosis and the prevalence of type IV hyperlipoproteinemia. Ann. intern. Med. 69, 21-33 (1968).

4. Kannel, W.B., Dawber, T.R., Friedman, G.D., Glennon, W.E., McNamara, P.M.: Risk factors in coronary heart disease: An evaluation of several serum lipids as predictors of coronary heart disease. Ann. intern. Med. 61, 888-899 (1964).

5. Albrink, M.J., Lavietes, P.H., Man, E.B.: Vascular disease and serum lipids in diabetes mellitus. Ann. intern. Med. 58, 305-323 (1963).

6. Kuo, P.T.: Hyperglyceridemia in coronary artery disease and its management. J. Amer. med. ass. 201, $101-108(1967)$.

7. Epstein, F.H.: Hyperglycomia. A risk factor in coronary heart disease. Circulation 36, 609-619 (1967).

8. Tzagournis, M., Chiles, R., Ryan, J.M., Skillman, T. G.: Interrelationships of hyperinsulinism and hypertriglyceridemia in young patients with coronary heart disease. Circulation 38, 1156-1163 (1968).

9. Levy, R.I., Glueck, C.J.: Hypertriglyceridemia, diabetes mellitus, and coronary vossel disease. Arch. intern. Med. 123, 220-228 (1969).

10. Abell, L.I., Levy, B.B., Brodie, B.B., Kondall, F.E. Simplified method of estimation of total cholesterol in serum and demonstration of its specificity. J. Biol. Chem. 195, 357 (1952).

11. Stern, I., Shapiro, B.: Rapid and simple method for determination of esterified fatty acids and for total fatty acids in blood. Brit. J. clin. Path. 6, 158 (1953).

12. Laurell, S.: Method for routine determination of plasma Triglycerides. Scand. J. Clin. and Lab. Invest. 18, $668-672(1966)$.

13. Fredrickson, D.S., Lees, R.S. : A system for phenotyping hyperlipoproteinemia. Circulation 31, 321 (1965).

14. - Levy, R.T., Lees, R.S.: Fat transport in lipoproteins: An integrated approach to mechanisms and disorders. New Engl. J. Med. 276, 32-44, 94-103, 148$156,215-226,273-281$ (1967).
15. Masket, B., Levy, R.I., Fredrickson, D.S.: A comparison of different familial hyperlipoproteinemia. Circulation 40, 3- 17 (1969).

16. Brown, H.B., Lewis, L.A., Page, I.H. : Mixed hyperlipidemia, an important type of hyperlipoproteinemia. Supp. VI to Circ. 37, 48 (1968).

17. Grodsky, G.M., Forsham, P.H.: Immunochemical assay of total extractable insulin in man. J. clin. Invest. 39, 1070 (1960).

18. Christakis, G., Rinzler, S.H., Archer, M., Kraus, A.: Effect of the anticoronary club diet program on coronary heart disease risk factor status. J. Amer. med. ass. 198, 129-136 (1966).

19. Wilkerson, H.L.C.: Diagnosis: Oral glucose tolerance tests. In diabetes Mellitus: Diagnosis and treatment. Edited by Danowski, T. S. Amer. Diabetes Assoc., Inc., N.Y. 1964, pp. 31-34.

20. Farquhar, J.W., Frank, A., Grosa, R.C., Reaven, G, M.: Glucose, insulin and triglyceride responses to high and low carbohydrate diets in man. J. clin. Invest. 45, $1648-1656$ (1966).

21. Reaven, G.M., Lerner, R.L., Stern, M.P., Farquhar, J.W.: Role of insulin in endogenous hypertriglyceridemia. J. clin. Invest. 46, 1756-1762 (1967).

22. Ford, S., Jr., Bozian, R.C., Knowles, H.C.: Interactions of obesity and glucose, and insulin levels in hypertriglyceridemia. Amer. J. clin. Nutr. 21, 904910 (1968).

23. Eden, M.A.M., Phauve, T.A.J.: Hyperinsulinism and carbohydrate-induced hyperlipoproteinaemia. The Lancet 1968 II, 264-265.

24. Hazard, W.R., Spiger, M.J., Bagdade, J.D., Bierman, E.L.: Studies on the mechanism of increased plasma triglyceride levels induced by oral contraceptives. New Engl. J. Med. 380, 471-474 (1969).

25. Zorrilla, E., Hulse, M., Hernandez, A., Gershberg, H.: Severe endogenous hypertriglyceridemia during treatment with estrogen and oral contraceptive. J. Clin. Endoc. \& Metab. 28, 1793-1796 (1968).

26. Glueck, C.J., Levy, R.I., Fredrickson, D.S.: Immunoreactive insulin, glucose tolerance, and carbohydrate inducibility in types II, III. IV, and V hyperlipoproteinemia. Diabetes 18, $739-747$ (1969).

27. Nikkila, E.A.: Control of plasma and liver triglyceride kinetics by carbohydrate metabolism and insulin. Advanc. in lipid research 7, 63 (1969).

28. Havel, R.J.: Conversion of plasma free fatty acids into triglycerides of plasma lipoprotein fractions in man. Metabolism 10, 1031-1034 (1961).

29. Boberg, J., Hallberg, D.: Changes in endogenous plasma triglycerides during elimination of exogenous triglycerides from the blood in man. J. Atherosclerosis Research 8, 351-356 (1968).

30. Tzagournis, M., Seidensticker, J.F., Hamwi, G.J.: Metabolic abnormalities in premature coronary disease: Effects of therapy. Ann. N.Y. Acad. Of sciences 148, 945-957 (1968).

M. Tzagournis, M.D.,

Department of Medicine,

Division of Endocrinology and Meta-

bolism,

The Ohio State University Hospitals,

Columbus, Ohio 43210, U.S.A. 